\title{
Various Items Causing IELTS Test-Taker's Low Performance in Mainland China: an International Joint Education Program Solution
}

\author{
Qinglan Yu \\ Department of English, North China Electric Power University, Beijing 102208, China \\ pwyql@aliyun.com
}

\begin{abstract}
Administered at local centers in 120 countries throughout the world, IELTS (International English Language Testing System) is one of the most widely used large-scale ESL tests that offer listening, writing, reading and speaking modules. In mainland China, students join in various international joint-education program, in which IELTS preparation course generally lasts more than 2 or 3 semesters, to get easier access to better universities abroad. Because of its popularity and its use for making critical decisions about test takers when they apply for a prestigious foreign university, it is crucial to draw attention to their high frequency of retaking IELTS test and their comparatively low performance and low learning efficiency. Therefore, the present paper aims to provide a descriptive and critical review of various reasons underlying Chinese IELTS candidate's low performance, including the historical and cultural difference between Chinese and English, the immaturity of current IELTS preparation course, the inadequacy of academic research about IELTS. Consequential course-design issues will also be discussed and suggestions will be given for building high-efficient IELTS preparation course.
\end{abstract}

Index Terms - IELTS, low performance, problems, solution, joint-education program

\section{Introduction}

International English Language Testing System is widely recognized as a large-scale ESL tests that also offer comprehensive examination for candidates, concerning reading, writing, listening and speaking component. In 2011, over 150 million candidates around the world have taken IELTS, among which there are over 300,000 Chinese testtakers (in mainland China) who received this international test in 48 test centers. Mainland China takes $50 \%$ of IELTS candidates in Asian area and applicants even have to wait in lines for a long time to register. This figure keeps growing at an alarming speed: every year we gain another five new testtakers who joined the team of "second-time or third-time" test takers and form a surprisingly enormous group. Among all these young, ambitious candidates, who dream of studying at, working in or immigrating to places where English is the main language of communication, a substantial amount of students are from international joint education programs of different universities. Generally, those programs, named as "2+2" program ( 2 years in a local university and 2 years abroad) or as " $3+1$ " program (3 years in a local university and 1 year abroad), are increasingly favored by those candidates for its high reliability, relatively low price, great convenience and time-saving. The present study takes North China Electric Power University (NCEPU) as an example. The involved students $(2+2$ candidates)are from the International School, who will have 2-years' preliminary study in China, and twoyears follow-up study in some prestigious British universities, like Cardiff University, University of Bath, University of Manchester, University of Edinburgh, or in some American Universities, like Purdue University, Illinois Institute of Technology ,etc., if they can meet the corresponding requirements, get good score in overall language ability and in each of the four skills. What the stakeholders expect to gain from specific score is reliable assessment of the applicant's academic competence in forthcoming study. In China, as the result of economic development and globalization, more than 1000 international joint education programs like "2+2" program or " $3+1$ " program have been gaining increasing popularity. Programs like this will generally provide IELTS preparation course, consulting service for school application and visa application, guidance on security principles in a new country, etc. It is not deniable that such programs have achieved fruitful outcomes: with appropriate schedule arrangement and scientific guidance, great amount of university students win the chance of receiving qualified education in developed countries. However, current survey indicates that a lot of students have taken this examination far more than one time for failing to get expected score, and the maximum number even amount to 9 times in 2 year. Particularly, a lot of Chinese students achieved very low score in speaking module and writing module, some even get 3.5 in speaking while with 6 in reading or listening. In NCEPU joint education program, third-time test-taker or forth-time test taker are so common around us that some people even take it for granted that a one-time victory is a "mission impossible". Worrying about their low performance, some students spent a lot of money to register in commercial training program, attempting to find a "short cut".

What cause the candidate's low performance? The present writer plans to reveal all the problems in current international joint education program based on social, psychological, and practical basis. Suggestions on how to improve the efficiency

\footnotetext{
* This work is supported by Beijing Higher Education Young Elite Teacher Project to Qinglan Yu
} 
of IELTS preparation course in " $2+2$ " or " $3+1$ " program would also be indicated.

\section{The Cultural Historical Inadequacy in Mainland China Students' Acquisition of English Competence}

With about over 5000 year's history, Chinese, a branch of Sino-Tibet language family, is the only official language in mainland China, having different bloodline from English, a branch of Indo-European language family. The physical distance between language system intrigue much greater difficulty in English learning and acquisition. Translation of classical works from source language into target language would not as easy as that between languages within one family, like from German into English. Differences in morphology, semantics, lexis, and syntax form huge gap between this two languages and brings great difficulty for learner's language acquisition and code switching.

With over 2,400 years' history of feudalism, China has formed unique history and culture, with its brilliant civilization, literature and language. Not like other Asian places like Singapore, Hongkong, China does not have a history of being a British colony, therefore, English, has always been a foreign language, rather than a second language within her territory. Nowadays, in China, some people with high education can read English newspaper, search specific information on his specified area or read articles, shop on line through Amazon or other websites, but they are not in authentic social environment to use English in everyday life. English is often limited to classroom language, which brings great difficulty for its development. A university professor can write research articles on his specified area might not be able to talk with a shop assistant fluently when he goes shopping in a New York grocery store. IELTS, as an effective way of assessing test-taker's real communicative competence, is a great challenge for average English learners, particularly in speaking and writing module.

\section{The Real Picture of IELTS Preparation Course in Most Joint-Education Program}

The greatest contradiction, as I noted, is the sharp gap between Chinese national English Assessment and Cambridge international English Examination Assessment. In most jointeducation program, students' IELTS preparation will be reinforced gradually and separated into various stages. In NCEPU, "2+2" program candidates are required to pass College English Test Band 4 (CET 4 )and College English Test Band 6 (CET 6) respectively in the first and second semesters, and to get at least 6 or 6.5 in IELTS test in the third semester. The transition between two extremely distinct assessment systems, and that between different assessing criteria, poses a great challenge for the test takers.

At the same time, in NCEPU, the syllabus design of " $2+2$ " program is not under any academic or scientific framework, since most international joint programs make selection of teaching and learning materials a random choice, decided by management in financial consideration or a particularly involved instructors' personal choice (Zhang Jing, 2010). In the International Communication School of NCEPU, Creative Reading has once "officially" selected as standard learning materials, however, they have been piled up in students bookshelves untouched, torturing teachers since it seems merely a wasting of time, or a trouble-maker, with not a single item of IELTS has been involved in.

What happened in the real preparation classroom? Actually, what has been intended international, interactive English classroom of " $2+2$ " program has more often than not been a tedious, torturing exercise time, dominated by mechanical training and repeated practice. Test-oriented teaching and learning dominate most international joint education programs and resulted in a tedious, tiring classroom. According to Zhang Jing's survey(Zhang Jing, 2010), most international joint education program claim the involvements of three types of teaching materials--- text books, supplementary materials and Cambridge IELTS authentic testing materials(from IELTS 1 to IELTS 9), to build a complete and systematic international joint program classroom. However, IELTS preparation course, new as it is, has never been in dominant position in college English learning. In China, for over about 30 years, to pass Band 4 examination (or better, Band 6 examination) has always been, and will be the minimum requirement for most non-English majors. Band 4 certificate actually plays a threshold role since most companies regard it as an starter criterion to judge whether their potential employees have basic English skills. College English teachers have rich experience in helping students pass this domestic and localized English test, and a lot of research articles could be found every year about its validity and reliability, strength and weaknesses, wash back effects and future development. In NCEPU, Band 4 teaching materials piled up everywhere, grades instructions (from Band 1 to Band 4)are so familiar to every teacher and student. However, in IELTS preparation course, people rarely get scientifically graded teaching materials, text book instructions have been diminished to the least amount, if not been abandoned totally. Supplementary materials, generally a mere personal choice of IELTS instructors, lack reasonable reliability and validity, are not emphasized either. Too much test-oriented as it is, IELTS preparation classroom has, to a great extent, undermined the interest and passion of its candidates.

However, what happened outside academic institutions forms a sharp contrast. In China, particularly in metropolis cities like Beijing, Shanghai, and Guangzhou, some milliondollar businesses relevant to IELTS, TOEFL or other English test mushroom in large scale and expand at enormous speed, and they get huge profit from book publishing, test preparation class, American or British university application consulting service ,etc.. Many candidates walk toward a diverging road--under the overwhelming pressure of getting 6 or 6.5 , surrounded by the hype and promise of some commercial test preparation center, which even claim that with the help of their created "treasury of skills and strategies", candidates might probably make the right choice for a reading comprehension 
question just with one glance of the original reading passage. Actually, a lot of test preparation centers do spend big budget to carefully examine their target test, and they do find "short cut" to improve candidates score in real test, provide "false" model articles or speaking prompts for test-takers to memorize mechanically. But this kind of improvement is by no means the progress of real language competence or communicative ability. Worse than that, it put poisonous weeds into Chinese English Language Education industry, and turned the original highly-efficient proficiency assessment into a game of "skills and strategies", which is supposed far from the imagination of the intelligent minds---the ESOL researchers and IELTS examiners. Principles of Communicative language testing (Weir, 1990) have not been really realized although those principles are underlying criterion of IELTS, if "skillequipped" test-takers satisfactorily got "false" high score and bragged about it everywhere.

\section{The Severe Poverty of Academic Research in IELTS Teaching and Learning}

Research in IELTS teaching and learning has long been ignored, which will in the long run harm its development and lead to huge wastage of social resources. With "IELTS" as the keyword of search on Http://dlib.edu.cnki.net (the most academic and professional website in China where academic researches, including research articles, conference report, master thesis and doctor dissertation are stored and can be downloaded if users pay the fee), 196 items (from the year 1990-2011) come up, and can be categorized as Table 1:

Table 1 IELTS Research Thesis and Articles (1990-2011)

\begin{tabular}{|c|c|c|c|c|}
\hline \multirow{4}{*}{$\begin{array}{l}\text { Thesis } \\
\text { (8 pieces) }\end{array}$} & Language Transfer & 1 & & \\
\hline & Backwash Effects & 1 & & \\
\hline & \multirow{2}{*}{$\begin{array}{l}\text { Individual Testing } \\
\text { Modules }\end{array}$} & \multirow{2}{*}{6} & Listening & 1 \\
\hline & & & Writing & 5 \\
\hline \multirow{16}{*}{$\begin{array}{c}\text { Articles } \\
(178 \\
\text { pieces })\end{array}$} & Skills\&Strategies & 65 & & \\
\hline & \multirow{2}{*}{ News\&Reports } & \multirow{2}{*}{51} & Common News\& Reports & 45 \\
\hline & & & Interviews & 6 \\
\hline & Implications & 15 & & \\
\hline & \multirow{2}{*}{$\begin{array}{l}\text { Assessment } \\
\text { Comparison }\end{array}$} & \multirow{2}{*}{15} & IELTS\&TOEFL & 5 \\
\hline & & & IELTS\&Other Assessments & 10 \\
\hline & \multirow{2}{*}{$\begin{array}{l}\text { Individual Testing } \\
\text { Modules }\end{array}$} & \multirow{2}{*}{20} & Practical Application & 8 \\
\hline & & & Theoretical Interpretation & 12 \\
\hline & \multirow{4}{*}{ Overall Research } & \multirow{4}{*}{5} & Objectiveness & 1 \\
\hline & & & Validity\&Reliability & 1 \\
\hline & & & Future Perspective & 1 \\
\hline & & & Existing Problems & 2 \\
\hline & \multirow{3}{*}{$\begin{array}{l}\text { International Joint } \\
\text { Program }\end{array}$} & \multirow{3}{*}{3} & Extracurriculum Activity & 1 \\
\hline & & & Backwash Effect & 1 \\
\hline & & & Implications & 1 \\
\hline & Others & 4 & & \\
\hline
\end{tabular}

From the Table I, with only 196 items in about 23 years, the comparative low effort and limited concern in academic research of IELTS have been shocking and unimaginable since it has been served as a milestone of English assessment in China and consumed over millions dollars each year during this period.

Firstly, what Chinese IELTS candidates concern most are articles about skills and strategies (65 articles) published in non-academic magazines(Shi Xiaoli, 2001; Liu Yun, 2010 Zhang Hongyan, 2008; Dong Fang, 2008 ,etc.).

Ranked second (51 articles)are the massive amount of news reports, interviews about high-scored candidate, announcement, introductory articles, which demonstrate a real market hit aroused by ITLTS in China(Tian Jin , 2010; Hu Ping, 2008; Du Song, 2006; Cui Weiwei,2005 ,etc.).

Thirdly, comparison between IELTS and local English assessment(IELTS\&CET4,IELTS\&CET6,

IELTS\&PET5 ,etc.) is made by academic researchers and professional instructors(15 articles and 10 M.A. theses), and they are particularly interested in a "who is better" game, putting IELTS and TOEFL in one basket and examine their differences and similarities(5 articles and 3 M.A. theses)(Liu Weiwei, 2008; Li Taoan, 2008; Zhang Shuqi,2006 ,etc.).

Fourthly, researchers and instructors are trying to learn from IELTS and write about the implications of IELTS on their college English teaching(15 articles) and they calls for a reform in Chinese local English assessment and instruction(Ma Yongfeng, 2009; Deng Zhong, 2008; Xu Ying, 2010 ,etc.).

What comes next is micro analysis (Xu Ying, 2010; Wang Jingjing, 2010, Yue Jianying, 2010 ,etc.) of each individual testing modules, namely, reading, writing, listening and speaking respectively(20 articles and 6 M.A. theses), and 12 articles apply linguistic, pedagogical or psychological theories to interpret the design of a certain module( $\mathrm{Yu}$ Fenlei, 2010; Shan Xiaohui, 2004; Jing Nan, 2007 ,etc..).

Conversely, in a 23-year-long period, only 5 researchers conduct an overall analysis of IELTS, in terms of its validity and reliability, objectiveness, future prospect and existing problems, which form a sharp contrast with those so called "IELTS experts" who dominate the front page of magazines and make "skills and strategies" extremely hot and crazy among the candidates (Chen Weidong, 1996; Li Qing, 2002; Ren Qin, 2010).

Lastly, 3 articles (Zhang Jing, 2010; Liu Baolong, 2010; Chen Lixin, 2009) involve the research of IELTS research under the background of international joint education program.

The three articles about international joint program are mainly written from peripheral perspectives or simple introductions, constructive suggestions on syllabus design or teaching materials, classroom activities, or assessment criterion are rare. Therefore, scientific, systematic research that can put English teaching or learning of international joint education program (such as " $2+2$ " program in NCEPU) compatible with, or closer to, the real, authentic framework of IELTS should be launched. The proportion of IELTS research is also shown in the following pie chart: 


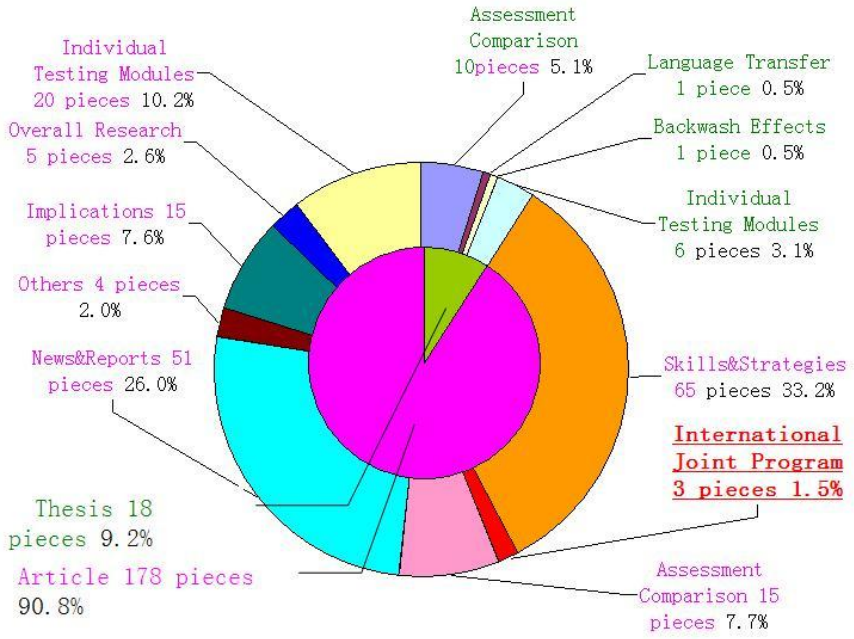

In 2014, with the same key word "IELTS" to search on CNKI, people can find 2048 pieces of items, which indicate a rapid increase in IELTS research. Is it an indication that adequate research efforts have been devoted to this area? If we use the key word "Band 4", 74455 results come out, with "Band 6", 13947 results. Therefore, it is reasonable to conclude that compared with national test like Band 4 or Band 6 , IELTS research still needs a lot of attention from academic professionals.

\section{Solutions to Improving the English-learning Efficiency and Performance of International Joint Education Program}

As for joint-education program, to help its participants get good GPA is very critical for them to apply for a satisfactory university. The truth is that most Chinese students get very high grade in science subjects, including math, physics, or chemistry because they have built very solid foundation during secondary education. When they study in English-speaking countries, they can easily cope with such subjects, work as teaching assistant or research assistant when they crossed language barrier. Therefore, to get at least 6 or 6.5 in IELTS will not only decide which university he or she would be enrolled in, but also indicate how fast he can adjust to life in a new academic environment, since IELTS score is very reliable indicator of English communicative competence. Then, it is reasonable for those joint-education program participants devote more time and effort in English learning, specifically-designed teaching syllabus, learning material, schedule arrangement and assessment.

Since most joint-education programs have two year's schooling in China, it is reasonable to design a four-semester project for IELTS preparation course, complying with the practical university and visa application. One important shift from current regular syllabus to an IELT-oriented syllabus could be to create a 3-step or 4-step learning procedure, not a simple "Band 4-Band 6-IELTS" ladder, but rearrangement of IELTS learning materials based on level of difficulty and learning purpose. A good reference to graded syllabus is
Common European Framework Reference (Strasbourg, 2005) (CEFR), which were developed independently of any specific language, and apply appropriate specifications to describing and governing scientific and systematic language education and assessment for a particular nation or culture, by sharing and benefiting from research fruits within three fields --Applied Linguistics, Language Testing and Assessment, and Corpus Linguistics. By having a detailed examination on CEFR, we could learn the methods of making Reference Level Description (RLD) under CEFR. Finally we will know how to design teaching program for a given purpose.

Similar to the six proficiency levels of CEFR that are currently applied in IELTS test throughout the world, (namely, A1 Breakthrough; A2 Way-stage; B1 Threshold; B2 Vantage; C1 Effective Operational Proficiency; and C2 Mastery), specific specifications for levels of achievement could be made in preliminary-IELTS learning of the " $2+2$ " program candidates in joint-education program, in line with the 9-band scoring of IELTS, and eliminate the simple classification of Band-4 learners, Band-6 learners and IELTS-learners, without detailed descriptors of developmental stages. Theoretical distinctions among developmental stages in IELTS candidates' English acquisition will be given, and would further contribute to improved diversities and validities of assessments.

Another meaningful work is a horizontal grouping of student learners, to identify defining or "criteria" features of Preliminary-IELTS proficiency levels for those would-be IELTS candidates, with each level characterized by a cluster of linguistic and communicative exponents.

With multiple grading criterion, IELTS candidates can choose preparation course to his level(skip stages much lower than his particular competence stages), or go through all the levels sequentially if he/she is an typical average learner.

Appropriate IELTS learning materials will play a very important role in classroom learning. Scientific teaching materials will change the current exercise-dominated classroom, increase learner's interest, accelerate teacherstudent interactions, optimize learning efficiency and virtually improve their performance in real test. Generally, in jointeducation program, to prepare students with best designed teaching materials, professional teachers should form a panel to select from existing teaching materials, including those imported from abroad, re-arrange them according to a specific syllabus, whether a function-notional, or a task-based, or more possible, a communicative syllabus.

To increase the efficiency of IELTS preparation course, large scale of survey should be carried out to investigate the learner expectations, their perceptions, the frequency and result of their test-taking, the wash back effect of IELTS on test takers and instructors.

From the perspective of teachers, they should on the one hand change their old role as a controller, into a monitor, counselor, consultant in the classroom, to put theory into practice, guiding their learning with meaningful theories, and put teaching activities under scientific framework; on the other hand, they should work with different kinds of materials if they 
want to create an IELTS preparation course where learners are encouraged to communicate in order to develop their own language learning---rather than to learn language in order to communicate.

Before we start to work, the key question of this discussion is thus the determination of exactly what the student or learner acquires in the IELTS preparation course. Does providing for a solid knowledge of language as such still remain the primary responsibility of the language teacher? Is it a combination of language structure, literature, culture, logic or anthropological issues including the way to deal with British or American transportation system, good citizenship, or the way to deal with your neighbors when suddenly moved to a totally-different country? Probably a proportional syllabus should be developed, putting different issues in appropriate proportion, directing the real process of classroom instruction.

The theoretical outcome of future research might include specific criterion in syntax, morphological-syntax and the lexicon exponents and criterion for communicative competence. Most probably, grading criterion for preliminaryIELTS candidates will be formed with sample level documents or videos. The concrete outcome of this research might be books and teaching materials, which would be edited accurately and scientifically according to working criterion mentioned above, and would serve as preliminary-IELTS teaching materials of " $2+2$ " program for the first two academic years.

\section{References}

[1] Zhang Jing. The Wash Back Effect of IELTS on English Teaching in Joint Education Program. Anhui Industry College Journal, 2010(3).

[2] Shi Xiaoli. Learning Strategies for Listening Sub-Test in IELTS. Teaching English in China, 2001(03).

[3] Liu Yun, IELTS Listening Module and College English Listening Strategy. Hubei Open University Journal, 2010(8).

[4] Zhang Hongyan. The Secret of IELTS Vocabulary. New Oriental English (College Version), 2008(1).

[5] Dong Fang. The Signal Word in IELTS Listening. 21 Century, 2008(9).

[6] Tian Jin. Stories Behind High IELTS Scores(III)—Chang Yifan's Implications. English Salon, 2010(10).
[7] Hu Ping. Opening Doors, Creating Opportunities_—An interview with IELTS representatives. English Salon, 2008(07).

[8] Du Song, IELTS International English Language Testing System. Overseas-Educated Scholars, 2006(03).

[9] Cui Weiwei. How to Register IELTS on Line. International Students, 2005(1).

[10] Liu Weiwei. A Comparison between PETS-5 Reading and CSC-ET Reading with Reference to Ielts Reading. Shanghai Foreign Studies University, 2008.

[11] Li Taoan. A Comparative Study on the Reading Comprehension Subtests of the New CET4, the Old CET4 and IELTS. Shanghai Foreign Studies University, 2008.

[12] Zhang Shuqi. A Comparative Analysis of Reading Tests in CET, TOEFL \& IELTS. Southeast University, 2006.

[13] Ma Yongfeng. Reflections on Chinese English test: an IELTS perspective. Mudanjiang College Journal, 2009(10).

[14] Deng Zhong. Implications of IELTS Reading Module on College English Reading Course. Xinan Minority University Journal, 2008(4).

[15] Xu Ying. The Leading in Function of IELTS "list of headings" questions. Fujian Technology College Journal, 2010(2).

[16] Wang Jingjing. The Authenticity of IELTS Listening Module and Current College English Speaking Test Reform. Liupanshui Teacher's College Journal, 2010(2).

[17] Yue Jianying. IELTS Speaking Module and Cross-Cultural Competence. Chinese Test(8).

[18] Yu Fenlei. The Function of "Narrow Listening" in IELTS Listening Class: a Schema perspective. Zhejiang Wangli College Journal, 2010(5).

[19] Shan Xiaohui. An Analysis on IELTS Writing from a Systemic Functional Grammar Perspective. University of Economy and Trade, 2004.

[20] Jing Nan. An Analysis on IELTS Writing from the Perspective of Cohesion and Coherence. Nanjing Normal University, 2007.

[21] Chen Weidong. On the Objectivity of the IELTS Test. Teaching English in China, 1996(2).

[22] Li Jing. The Current Development of IELTS and Its Prospect in China. Shenyang Agriculture University Journal, 2002(1).

[23] Ren Qin. A Concise Review of the IELTS Speaking Test: Validity, Reliability, and Practicality Thinking, 2010(s1).

[24] Chen Lixin. Implications of IELTS on High Vocational College Joint Education Program. Modern Business and Agriculture, 2009(1).

[25] Reference Level Descriptions for National and Regional Languages (version 2), 2005. Strasbourg: Language Policy Division, Council of Europe. http://www.coe.int/lang. 